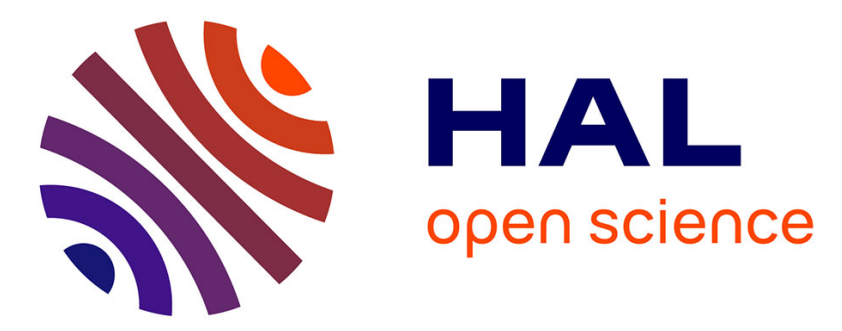

\title{
A Fluorinated Bola-Amphiphilic Dendrimer for On-Demand Delivery of siRNA, via Specific Response to Reactive Oxygen Species
}

Xiaoxuan Liu, Yang Wang, Chao Chen, Aura Tintaru, Yu Cao, Juan Liu, Fabio Ziarelli, Jingjie Tang, Hongbo Guo, Roseline Rosas, et al.

\section{To cite this version:}

Xiaoxuan Liu, Yang Wang, Chao Chen, Aura Tintaru, Yu Cao, et al.. A Fluorinated Bola-Amphiphilic Dendrimer for On-Demand Delivery of siRNA, via Specific Response to Reactive Oxygen Species. Advanced Functional Materials, 2016, 26 (47), pp.8594-8603. 10.1002/adfm.201604192 . hal-01459079

\section{HAL Id: hal-01459079 https://hal.science/hal-01459079}

Submitted on 30 Mar 2018

HAL is a multi-disciplinary open access archive for the deposit and dissemination of scientific research documents, whether they are published or not. The documents may come from teaching and research institutions in France or abroad, or from public or private research centers.
L'archive ouverte pluridisciplinaire HAL, est destinée au dépôt et à la diffusion de documents scientifiques de niveau recherche, publiés ou non, émanant des établissements d'enseignement et de recherche français ou étrangers, des laboratoires publics ou privés. 


\title{
A fluorinated bola-amphiphilic dendrimer for on-demand delivery of siRNA via specific response to reactive oxygen species
}

\author{
Xiaoxuan Liu, ${ }^{a, b, c}$ Yang Wang, ${ }^{a}$ Chao Chen, ${ }^{a, d}$ Aura Tintaru, ${ }^{d}$ Yu Cao, ${ }^{a}$ Juan Liu, ${ }^{a}$ Fabio Ziarelli, ${ }^{e}$ Jingie \\ Tang, ${ }^{a}$ Hongbo Guo, ${ }^{f}$ Roseline Rosas, ${ }^{e}$ Suzanne Giorgio, ${ }^{a}$ Laurence Charles, ${ }^{d}$ Palma Rocchi, ${ }^{b}$ Ling \\ Peng $^{a * *}$
}

a Aix-Marseille Université, CNRS, Centre Interdisciplinaire de Nanoscience de Marseille, UMR 7325, « Equipe Labellisée Ligue Contre le Cancer », 13288 Marseille, France

${ }^{b}$ Aix-Marseille Université, CNRS, INSERM, Institut Paoli-Calmettes, Centre de Recherche en Cancérologie de Marseille, UMR1068, Marseille, France

${ }^{c}$ Present address: State Key Laboratory of Natural Medicines and Jiangsu Key Laboratory of Drug Discovery for Metabolic Diseases, Center of Drug Discovery, China Pharmaceutical University, 210009 Nanjing, China

${ }^{d}$ Aix-Marseille Université, CNRS, UMR 7273, Institut de Chimie Radicalaire, 13397 Marseille, France; ${ }^{e}$ Aix-Marseille Université, CNRS, FR1739, Fédération des Sciences Chimiques de Marseille, 13397 Marseille, France

${ }^{f}$ CAS Key Laboratory for Biomedical Effects of Nanomaterials and Nanosafety, National Center for Nanoscience and Technology of China, 100190 Beijing, China

Address correspondence to:

Ling Peng, Ph.D.

ling.peng@univ-amu.fr 


\begin{abstract}
Functional materials capable of responding to stimuli intrinsic to diseases are extremely important for specific drug delivery at the disease site. However, developing on-demand stimulus-responsive vectors for targeted delivery is highly challenging. Here, we report a stimulus-responsive fluorinated bola-amphiphilic dendrimer for on-demand delivery of small interfering RNA (siRNA) in response to the characteristic high level of reactive oxygen species (ROS) in cancer cells. This dendrimer bears a ROS-sensitive thioacetal in the hydrophobic core and positively charged poly(amidoamine) dendrons at the terminals, capable of interacting and compacting the negatively charged siRNA into nanoparticles to protect the siRNA and promote cellular uptake. The ROS-sensitive feature of this dendrimer boosted specific and efficient disassembly of the siRNA/vector complexes in ROS-rich cancer cells for effective siRNA delivery and gene silencing. Moreover, the fluorine tags in the vector enabled ${ }^{19} \mathrm{~F}-\mathrm{NMR}$ analysis of the ROS-responsive delivery process. In addition, this ingenious and distinct bolaamphiphilic dendrimer is also able to combine the advantageous delivery features of both lipid and dendrimer vectors. Therefore, it represents an innovative on-demand stimulus-responsive delivery platform based on dendrimer molecular engineering.
\end{abstract}

Key words: bola-amphiphile, stimuli-responsive, siRNA delivery, gene therapy, ${ }^{19} \mathrm{~F}-\mathrm{NMR}$, 


\section{INTRODUCTION}

Molecular science has revolutionized the central paradigm of drug delivery, especially for establishing smart or intelligent materials to deliver therapeutic agents on-demand. ${ }^{1-3}$ In particular, many of the advances in the design of delivery systems for anticancer therapeutics has been inspired by a growing understanding of tumor microenvironments and exploitation of specific characteristics of cancer cells and subtle difference in tumor lesions., ${ }^{1,2,4}$ Tumor microenvironments are characterized by a variety of atypical features such as abnormal tumor vasculature, absence of lymphatic drainage, altered redox environment, hypoxia and lower $\mathrm{pH}$ gradient etc. ${ }^{5}$ It is of note that an intrinsic factor specifically linked to cancer cells is the high level of reactive oxygen species (ROS), as ROS are constantly generated within cancer cells because of the highly stressful environment caused by rapid and uncontrollable cancer cell proliferation. ${ }^{6,7}$ Despite the obvious interest in harnessing this factor for specific targeting in cancer treatment, few strategies have been explored to develop delivery systems that are capable of ROS-triggered controlled release, in particular for small interfering RNA (siRNA) therapeutics. ${ }^{8,9}$

Therapeutics based on siRNA provide an enormous opportunity for cancer treatment by virtue of the ability of siRNA to specifically and efficiently turn off the expression of genes associated with cancer development and drug resistance. ${ }^{10-12}$ However, the main challenge facing siRNA therapeutics is their safe and efficient delivery. ${ }^{13,14}$ This is because siRNA is too negatively charged to spontaneously cross biomembranes; at the same time, siRNA is vulnerable to nuclease attack. Consequently, safe and efficient on-demand delivery vectors, which can prevent siRNA degradation and convey functional siRNA into cancer cells, are in high demand.

During the past years, various natural and synthetic delivery systems have been developed for siRNA delivery. Among these, the most effective are viral vectors. However, because of concerns about the immunogenicity and safety of viral delivery systems, there is an urgent demand for developing the alternative nonviral vectors. ${ }^{13,14}$ The two main classes of nonviral vectors are based on lipids and polymers. ${ }^{14-17}$ Dendrimers, a special type of synthetic polymer, have recently emerged as a promising delivery platform for siRNA therapeutics by virtue of 
their well-defined and precisely-controlled molecular structures as well as the unique multivalent cooperativity confined within a nanoscale volume. ${ }^{18,19}$ In particular, amphiphilic dendrimers with judiciously tailored hydrophilic and hydrophobic components are able to benefit from the combined advantages of lipid and dendrimer vectors for effective siRNA delivery. ${ }^{20-22}$

Here, we report an innovative bola-amphiphilic dendrimer bola4A for on-demand delivery of siRNA in response to the high level of ROS in cancer cells (Figure 1). This dendrimer features a bola-lipid/dendrimer hybrid harboring a ROS-sensitive thioacetal group at the central hydrophobic core and two poly(amidoamine) (PAMAM) dendrons as the polar terminals (Figure 1A). The PAMAM dendrons, which bear amine terminals and are positively charged at physiological $\mathrm{pH}$, have been devised to interact with the negatively charged siRNA via electrostatic interactions, ${ }^{23}$ while the hydrophobic "bola-lipid" core scaffold is to mimic the robust and strong assembly properties of bola-amphiphiles observed in extremophile archae bacteria. ${ }^{24}$ The thioacetal entity at the bola-lipid core is supposed to decompose upon exposure to the high level of ROS in cancer cells, ${ }^{8,9}$ thereby promoting siRNA unpacking for potent gene silencing within cancer cells (Figure 1B). Also of note is the presence of fluorine tags within this vector, which allow tracking of the ROS-responsive delivery process by ${ }^{19} \mathrm{~F}-\mathrm{NMR} .{ }^{25}$ Last but not least, this distinctive and ingenious bola-amphiphilic vector, by combining the advantages of both lipid and dendrimer vectors, will provide a new perspective on the design of ROS-responsive vectors for targeted siRNA delivery.

\section{RESULTS AND DISCUSSION}

Dendrimer bola4A is readily synthesized via "click" chemistry. We synthesized bola4A according to the plan illustrated in Scheme 1 (and in Scheme S1 in supplementary materials). The bola-core 1 was prepared via the condensation of 3,5-difluorobenzaldehyde with the freshly prepared corresponding azido-bearing thiol in the presence of the Lewis acid catalyst trifluoroboronetherate. ${ }^{26,27}$ Using the Cu-catalyzed Huisgen "Click" reaction, ${ }^{20,21,28}$ we successfully conjugated the bola-core $\mathbf{1}$ with the alkynyl-terminated dendron $\mathbf{2}$ to yield $\mathbf{3}$. The bola-dendrimer 3 was subsequently subjected to amidation with ethylenediamine to provide 
the desired bola4A. After purification via dialysis, bola4A was obtained in excellent purity with yield exceeding $90 \%$.

Bola4A responds to ROS. With the bola-dendrimer bola4A in hand, we investigated its response to ROS under simulated conditions, that is, in the presence of $\mathrm{H}_{2} \mathrm{O}_{2}$ (Figure 2). We incubated bola4A with $\mathrm{H}_{2} \mathrm{O}_{2}$ and found that the sharp ${ }^{19} \mathrm{~F}-\mathrm{NMR}$ signal originating from the intrinsic fluorine atoms of bola4A $(\delta=-110.5 \mathrm{ppm})$ disappeared rapidly, while new ${ }^{19} \mathrm{~F}-\mathrm{NMR}$ peaks associated with the degradation products of bola4A progressively appeared (Figure 2A and Figure S1). This finding implies that bola4A was decomposed following exposure to $\mathrm{H}_{2} \mathrm{O}_{2}$. Subjecting the same samples to electrospray ionization mass spectrometry (ESI-MS) further confirmed the degradation of bola4A upon treatment with $\mathrm{H}_{2} \mathrm{O}_{2}$ (Figure 2B). On the one hand, signals assigned to bola4A in multiple protonation states (from $3+$ to $6+$ ) were observed to decrease and disappear as a function of the $\mathrm{H}_{2} \mathrm{O}_{2}$ exposure time (Figure 2B). On the other hand, new signals detected during the $\mathrm{H}_{2} \mathrm{O}_{2}$ treatment indicated the decomposition of bola4A and the formation of degradation products (Figure 2B). Based on the elemental composition derived from the accurate mass measurements (Table S1), structures could be proposed for these degradation products (Figure 2C), highlighting the effective disintegration of the thioacetal function after exposure to $\mathrm{H}_{2} \mathrm{O}_{2}$. Collectively, these results demonstrate that bola4A is readily decomposed under ROS conditions, and hence possesses favorable properties for potential controlled release in response to ROS.

\section{Bola4A forms nanoparticles with siRNA, protects siRNA and promote cellular uptake.}

For siRNA delivery, it is important that the delivery vector is able to bind and condense the siRNA into nanosized complexes and protect it from degradation before promoting its cellular uptake. With this in mind, we examined the formation of siRNA/bola4A complexes using gel shift analysis. As shown in Figure 3A, bola4A was able to form stable complexes with siRNA and completely retard the migration of siRNA on the gel at an $\mathrm{N} / \mathrm{P}$ ratio $\geq 2.5$. Further results from transmission electron microscopy (TEM) and scanning electron microscopy (SEM) revealed that the resulting siRNA/bola4A complexes formed uniform, compact and spherical nanoparticles (Figures 3B and 3C). Additional dynamic light scattering (DLS) analysis 
confirmed that the siRNA/bola4A nanoparticles were well dispersed with a size average of 50 $\mathrm{nm}$ (Figure 3D). The surface charge of these nanoparticles was characterized by a $\zeta$-potential of $+28 \mathrm{mV}$, implying stable colloidal nanoparticles. Indeed, the so-formed siRNA/bola4A nanoparticles effectively protected the siRNA from degradation by the enzyme RNase (Figure 3E), further indicating the formation of stable siRNA/bola4A complexes. Finally, these siRNA/bola4A nanoparticles were rapidly and efficiently internalized by cells (Figure 3F), a benefit and advantageous prerequisite for effective siRNA delivery.

Bola4A/siRNA complexes are responsive to ROS. Importantly, the siRNA/bola4A nanoparticles were readily disassembled in response to high ROS levels in cancer cells. We first studied the siRNA/bola4A nanoparticles in response to $\mathrm{H}_{2} \mathrm{O}_{2}$, which simulates ROS conditions. As shown by TEM imaging, the siRNA/bola4A nanoparticles collapsed upon exposure to $\mathrm{H}_{2} \mathrm{O}_{2}$, accompanied by a significant change in morphology, suggesting a ROStriggered disassembly of the siRNA/bola4A complexes (Figure 4A and Figure S2). In line with the TEM imaging, further results from DLS analysis (Figure S3) also indicated the destruction of the siRNA/bola4A nanoparticles upon treatment with $\mathrm{H}_{2} \mathrm{O}_{2}$.

Moreover, we examined the ROS-triggered decomposition of bola4A once the siRNA/bola4A complexes were internalized into ROS-abundant human prostate cancer PC-3 cells. To do this, we used ${ }^{19} \mathrm{~F}$ high-resolution magic angle spinning (HRMAS) NMR, a nondestructive method for in situ analysis of ${ }^{19} \mathrm{~F}$-containing compounds within intact cells. ${ }^{19} \mathrm{~F}$ HRMAS NMR is particularly powerful and sensitive for investigating fluorinated bola4A in cells since there are no endogenous fluorinated compounds in cells, and hence no ${ }^{19} \mathrm{~F}-\mathrm{NMR}$ signal in the control background. ${ }^{25,29,30}$ As shown in Figure 4B, only weak ${ }^{19}$ F-NMR signals were observed in ROS-abundant prostate cancer PC-3 cells, although FACS flow cytometry demonstrated that the siRNA/bola4A complexes were rapidly and effectively taken up by PC3 cells (Figure $3 \mathrm{~F}$ ). In contrast, a sharp, strong and singular ${ }^{19} \mathrm{~F}-\mathrm{NMR}$ signal was detected in ROS-depleted PC-3 cells which were pretreated with the antioxidant N-acetyl cysteine (NAC) (Figure 4C). It is of note that treating PC-3 with the antioxidant NAC effectively downregulated the ROS level significantly (Figure 5A). In addition, the chemical shift of the ${ }^{19} \mathrm{~F}$ NMR signal detected in the NAC-treated PC-3 cells was a perfect match with that of bola4A, 
indicating that bola4A maintained intact in ROS-poor PC-3 cells pretreated with the antioxidant NAC. Similar results were also observed with ROS-poor Chinese hamster ovary (CHO) cells (Figure 4D). Collectively, these results indicate that bola4A was indeed decomposed or metabolized in ROS-rich PC-3 cells, but not in ROS-poor CHO or antioxidanttreated low-ROS PC-3 cells. Thus, bola4A demonstrates effective ROS-responsiveness for cancer cells.

\section{Bola4A-mediated specific ROS-responsive delivery of siRNA and gene silencing.} Encouraged by the ROS-responsive properties of our bola4A dendrimer, we evaluated its ability to deliver siRNA and inhibit gene expression in two high-ROS cell lines, human prostate cancer PC-3 cells and breast cancer MCF-7 cells, and three low-ROS cell lines, human embryonic kidney (HEK) cells, Chinese hamster ovary (CHO) cells and antioxidant-pretreated PC-3 cells (Figure 5). The siRNA molecules used in this study were devised to target either heat shock protein $27(\mathrm{Hsp} 27)^{31,32}$ or translationally controlled tumor protein (TCTP) ${ }^{33,34}$, both of which are actively involved in cancer development and drug resistance. Following bola4Amediated siRNA delivery, expression of Hsp27 and TCTP was considerably suppressed in the two high-ROS content cancer cell lines PC-3 (Figure 5B) and MCF-7 (Figure 5C), whereas no noticeable gene silencing was observed in the low-ROS content HEK (Figure 5D) and CHO cells (Figure 5E). This can be reasonably ascribed to the inherently higher level of ROS in cancer cells, which leads to the decomposition of bola4A and consequently the disassembly of the siRNA/bola4A complexes, thereby enhancing siRNA release and gene silencing.

We further demonstrated that down-regulation of the ROS level in PC-3 cells by pretreatment with the antioxidant NAC (Figure 5A) led to a dramatic decrease in gene silencing (Figure 5F). This provides additional evidence that gene silencing is specifically triggered by ROS. Together, our results indicate that bola4A is able to mediate specific and efficient siRNA delivery and gene silencing in response to a ROS-rich environment, in perfect agreement with our design concept for bola4A as a ROS-responsive vector.

Bola4A benefits from the integrated delivery advantages of lipid and dendrimer vectors. In addition to the ROS-responsive feature of bola4A, we wanted to forge a strong and stable 
vector based on our bola-amphiphile by combining the benefits of both lipid and PAMAM dendrimer vectors for siRNA delivery. ${ }^{20,21}$ Our bola4A is a lipid/dendrimer hybrid bearing a hydrophobic chain entity and two hydrophilic PAMAM dendrons (Figure 1A). When we compared the gene silencing activity of bola4A with mono4A (the amphiphilic dendrimer without the bola-lipid core), dendron4A (the dendron entity alone) or the bola-core 1, only bola4A was effective (Figure 6A). Thus, the unique bola-amphiphilic architecture did indeed endow bola4A with the ability to deliver siRNA effectively. It is to mention that the hydrophobic bola-core in bola4A is shorter than the native phospholipid bilayer. We designed bola4A with this unique molecular architecture to avoid insertion into the cell membrane, thus obviating deleterious effects on cell membrane integrity and cell viability. The biocompatibility of bola4A was confirmed by the absence of serum hemolysis (Figure S4) and cytotoxicity using both lactate dehydrogenase (LDH) and MTT tests (Figure S5). We further examined bola4A-mediated siRNA delivery and gene silencing in the presence of dioleoylphosphatidylethanolamine (DOPE). DOPE is a fusogenic lipid, which promotes fusion and is frequently used to enhance the delivery efficacy of lipid vectors. Our results showed that gene silencing was significantly increased in the presence of DOPE (Figure 6B), confirming that bola4A is endowed with the delivery characteristics of lipid vectors.

We also surmised that bola4A might profit from the "proton sponge effect" 35 of PAMAM dendron entities for effective nucleic acid delivery. The proton sponge phenomenon occurs for PAMAM dendrimers in acidic environments such as endosomes, and is thought to be important for release of the cargo from endosomes into the cytoplasm. The tertiary amine groups in the interior of the PAMAM dendron are ready to mop up protons within endosomes (Figure S6), leading to an ionic imbalance which results in endosomal lysis and cargo release. We used the proton pump inhibitor bafilomycin A1 to impede endosome acidification, in order to test whether endosomal acidification affects bola4A-mediate siRNA delivery and gene silencing. Indeed, treatment with bafilomycin A1 significantly lowered the level of Hsp27 expression (Figure 6C), suggesting that acidic endosomes are necessary for effective siRNA release and delivery by bola4A. This result is consistent with the hypothesis that the PAMAM dendrons act as a proton sponge, and that this property is important for siRNA delivery. 


\section{CONCLUSION}

In conclusion, we have established a ROS-sensitive bola-amphiphilic dendrimer bola4A as an innovative on-demand vector for stimulus-responsive siRNA delivery and gene silencing. The so-devised bola4A is also able to benefit from the combined advantages of lipid and dendrimer vectors. The distinctive ROS-sensitive thioacetal motif within bola4A allows efficient disassembly of the siRNA/bola4A complexes under ROS-rich conditions for effective siRNA delivery and potent gene silencing in cancer cells. In addition, the presence of fluorine atoms within this vector makes it possible to study the ROS-responsive delivery process by ${ }^{19}$ F-NMR. Collectively, our results show that this ROS-sensitive bola-amphiphilic dendrimer offers a unique opportunity to achieve controllable release of siRNA for effective gene silencing in cancer cells by capitalizing on the high level of intracellular ROS. Our study provides a new perspective on the design of tailor-made stimulus-responsive materials for ondemand drug delivery.

\section{ASSOCIATED CONTENT}

Supporting information: supplementary figures, materials and methods, dendrimer synthesis and characterization as well as all experimental protocols for NMR, MS, TEM, DLS, cell uptake, siRNA delivery, gene silencing etc. This information is available free of charge via Internet.

\section{ACKNOWLEDGEMENTS}

Financial support from La Ligue Nationale Contre le Cancer (LP), Association pour la Recherche sur les Tumeurs de la Prostate (LP, XL), Association Française contre les Myopathies (XL), Fondation pour la Recherche Médicale (YC), the international ERA-Net EURONANOMED European Research project “Target4Cancer” (LP), China Scholarship Council (YW, CC, JL, JT), PACA Canceropôle, INCa, CNRS and INSERM is gratefully acknowledged. We thank Serge Netische and Damien Chaudanson for SEM experiments, 
Yaling Gan for TEM experiments and Alice Carrier for advice about ROS experiments.

\section{AUTHOR INFORMATION}

LP conceived the project. XL, YW, LP designed experiments, YW, CC, YC and JT synthesized the dendrimer, AT, FZ, RR and LC executed MS and NMR analysis, CC, JT, SG, HG performed TEM and DLS experiments, XL carried out all biological experiments with the help of PR and JL. XL and LP wrote the manuscript with comments from all the other authors.

\section{REFERENCES:}

(1) Mura, S.; Nicolas, J.; Couvreur, P. Nat. Mater. 2013, 12, 991.

(2) Torchilin, V. P. Nat. Rev. Drug Discov. 2014, 13, 813.

(3) Blanco, E.; Shen, H.; Ferrari, M. Nat Biotech 2015, 33, 941.

(4) Chauhan, V. P.; Jain, R. K. Nat. Mater. 2013, 12, 958.

(5) Joyce, J. A.; Pollard, J. W. Nature Reviews Cancer 2009, 9, 239.

(6) Gorrini, C.; Harris, I. S.; Mak, T. W. Nat. Rev. Drug Discov. 2013, 12, 931.

(7) Trachootham, D.; Alexandre, J.; Huang, P. Nat. Rev. Drug Discov. 2009, 8, 579.

(8) Shim, M. S.; Xia, Y. Angew. Chem. Int. Ed. 2013, 52, 6926.

(9) Wilson, D. S.; Dalmasso, G.; Wang, L.; Sitaraman, S. V.; Merlin, D.; Murthy, N. Nat. Mater. 2010, 9 , 923.

(10) Castanotto, D.; Rossi, J. J. Nature 2009, 457, 426.

(11) Crunkhorn, S. Nat. Rev. Drug Discov. 2013, 12, 178.

(12) Haussecker, D.; Kay, M. A. Science 2015, 347, 1069.

(13) Whitehead, K. A.; Langer, R.; Anderson, D. G. Nat. Rev. Drug Discov. 2009, 8, 129.

(14) Kanasty, R.; Dorkin, J. R.; Vegas, A.; Anderson, D. Nat. Mater. 2013, 12, 967.

(15) Tseng, Y. C.; Mozumdar, S.; Huang, L. Adv. Drug Deliv. Rev. 2009, 61, 721.

(16) Davis, M. E.; Zuckerman, J. E.; Choi, C. H.; Seligson, D.; Tolcher, A.; Alabi, C. A.; Yen, Y.; Heidel, J. D.; Ribas, A. Nature 2010, 464, 1067.

(17) Wagner, E. Acc. Chem. Res. 2012, 45, 1005.

(18) Khandare, J.; Calderón, M.; Dagia, N. M.; Haag, R. Chem. Soc. Rev. 2012, 41, 2824.

(19) Liu, X.; Rocchi, P.; Peng, L. New J. Chem. 2012, 36, 256.

(20) Yu, T.; Liu, X.; Bolcato-Bellemin, A. L.; Wang, Y.; Liu, C.; Erbacher, P.; Qu, F.; Rocchi, P.; Behr, J. P.; Peng, L. Angew. Chem. Int. Ed. 2012, 51, 8478.

(21) Liu, X.; Zhou, J.; Yu, T.; Chen, C.; Cheng, Q.; Sengupta, K.; Huang, Y.; Li, H.; Liu, C.; Wang, Y.; Posocco, P.; Wang, M.; Cui, Q.; Giorgio, S.; Fermeglia, M.; Qu, F.; Pricl, S.; Shi, Y.; Liang, Z.; Rocchi, P.; Rossi, J. J.; Peng, L. Angew. Chem. Int. Ed. 2014, 53, 11822.

(22) Chen, C.; Posocco, P.; Liu, X.; Cheng, Q.; Laurini, E.; Zhou, J.; Liu, C.; Wang, Y.; Tang, J.; Col, V. D.; Yu, T.; Giorgio, S.; Fermeglia, M.; Qu, F.; Liang, Z.; Rossi, J. J.; Liu, M.; Rocchi, P.; Pricl, S.; Peng, L. Small 2016, $12,3667$. 
(23) Zhou, J.; Wu, J.; Hafdi, N.; Behr, J. P.; Erbacher, P.; Peng, L. Chem. Commun. 2006, 2362.

(24) Valentine, D. L. Nat. Rev. Microbiol. 2007, 5, 316.

(25) Chen, H.; Viel, S.; Ziarelli, F.; Peng, L. Chem. Soc. Rev. 2013, 42, 7971.

(26) Xia, Y.; Viel, S.; Wang, Y.; Ziarelli, F.; Laurini, E.; Posocco, P.; Fermeglia, M.; Qu, F.; Pricl, S.; Peng, L. Chem. Commun. 2012, 48, 4284.

(27) Xia, Y.; Sengupta, K.; Maggiani, A.; Qu, F.; Peng, L. Org. Biomol. Chem. 2013, 11, 5000.

(28) Kolb, H. C.; Finn, M. G.; Sharpless, K. B. Angew. Chem. Int. Ed. Engl. 2001, 40, 2004.

(29) Ziarelli, F.; Peng, L.; Zhang, C.-C.; Viel, S. J. Pharm. Biomed. Anal. 2012, 59, 13.

(30) Griffin, J. L.; Pole, J. C.; Nicholson, J. K.; Carmichael, P. L. Biochim. Biophys. Acta. 2003, 1619, 151.

(31) Rocchi, P.; Beraldi, E.; Ettinger, S.; Fazli, L.; Vessella, R. L.; Nelson, C.; Gleave, M. Cancer Res. 2005, $65,11083$.

(32) Rocchi, P.; So, A.; Kojima, S.; Signaevsky, M.; Beraldi, E.; Fazli, L.; Hurtado-Coll, A.; Yamanaka, K.; Gleave, M. Cancer Res. 2004, 64, 6595.

(33) Baylot, V.; Andrieu, C.; Katsogiannou, M.; Taieb, D.; Garcia, S.; Giusiano, S.; Acunzo, J.; Iovanna, J.; Gleave, M.; Garrido, C.; Rocchi, P. Cell Death Dis. 2011, 2, e221.

(34) Bommer, U. A.; Thiele, B. J. Int. J. Biochem. Cell Biol. 2004, 36, 379.

(35) Behr, J. P. Chimia 1997, 51, 34. 


\section{Figure legends:}

Scheme 1: Synthesis of the bola-amphiphilic dendrimer bola4A.

Figure 1: The bola-amphiphilic dendrimer bola4A, designed for ROS-responsive siRNA delivery. (A) Chemical structure of bola4A. (B) Schematic representation of bola4A for the ROS-triggered delivery of siRNA and consequential gene silencing. Bola4A dendrimers form complexes with siRNA molecules, which can be internalized by the cancer cell before releasing siRNA in response to ROS, leading to effective gene silencing.

Figure 2: Study of bola4A decomposition upon treatment with $200 \mathrm{mM} \mathrm{H}_{2} \mathrm{O}_{2}$ (simulated ROS conditions) for 0, 2 and $24 \mathrm{~h}$, using (A) ${ }^{19}$ F-NMR and (B) ESI-MS analysis. (C) Proposed structures, based on accurate mass measurements (Table S1), of degradation products of bola4A formed upon treatment with $\mathrm{H}_{2} \mathrm{O}_{2}$.

Figure 3: Bola4A is able to form nanocomplexes with siRNA, protect siRNA from degradation and promote cellular uptake. (A) Agarose gel migration of siRNA (200 ng per well) in the presence of bola4A dendrimer at N/P charge ratios of 1/5 - 10/1. (B) TEM image of the siRNA/bola4A complexes using $5 \mathrm{ng} / \mu \mathrm{L}$ siRNA and bola4A at an N/P ratio of 10. (C) SEM image of the siRNA/bola4A complexes using $5 \mathrm{ng} / \mu \mathrm{L}$ siRNA and bola4A at an N/P ratio of 10. (D) Size distribution of the siRNA/bola4A complexes (at an N/P ratio of 10 with $1 \mu \mathrm{M}$ siRNA) determined using DLS. (E) Protection of siRNA by bola4A against enzymatic degradation. Compared to the naked siRNA (200 ng per well) which was degraded within 5 min in the presence of RNase, siRNA complexed with bola4A at an N/P ratio of 10 was resistant to RNase and remained stable even after $1 \mathrm{~h}$ incubation. (F) Uptake of Dy647-labeled Hsp27 siRNA/bola4A complexes (at an N/P ratio of 10 with $50 \mathrm{nM}$ siRNA) by human prostate cancer PC-3 cells evaluated using flow cytometry. Experiments were carried out in triplicate.

Figure 4: (A) TEM images of siRNA/bola4A complexes $(\mathrm{N} / \mathrm{P}=10)$ before and after incubation with $\mathrm{H}_{2} \mathrm{O}_{2}(1.06 \mathrm{M})$ for 2,4 and $24 \mathrm{~h}$ at $37{ }^{\circ} \mathrm{C}$. Scale bars indicate $200 \mathrm{~nm} .{ }^{19} \mathrm{~F}$ HRMAS NMR recording of bola4A at different time points $(0,1,2$ and $4 \mathrm{~h})$ in (B) ROS-rich normal prostate cancer PC-3 cells, (C) ROS-poor PC-3 cells pretreated with the antioxidant N-acetyl cysteine (NAC) and (D) ROS-poor Chinese hamster ovary (CHO) cells after treatment with the 
siRNA/bola4A complexes.

Figure 5: Bola4A-mediated specific and efficient ROS-responsive siRNA delivery and gene silencing. (A) ROS levels in Chinese hamster ovary (CHO) cells, human embryonic kidney (HEK) cells, breast cancer MCF-7 cells, prostate cancer PC-3 cells, and PC-3 cells pretreated with the antioxidant $\mathrm{N}$-acetyl-cysteine (NAC) $(10 \mathrm{mM})$ quantified using CellROX ${ }^{\circledR}$ orange reagent by flow cytometry. Bola4A-mediated siRNA delivery and gene silencing in ROSabundant (B) PC-3 cells and (C) MCF-7 cells, as well as in ROS-poor (D) HEK cells, (E) CHO cells and (F) PC-3 cells pretreated with NAC (50 nM siRNA at N/P=10). SiRNAs targeting heat shock protein 27 (Hsp27) and translationally controlled tumor protein (TCTP) were used.

Figure 6: Bola4A-mediated siRNA delivery benefits from both the distinctive bolaamphiphilic structure and the delivery features of lipid and dendrimer vectors. (A) Compared to bola4A, neither the amphiphilic dendrimer mono4A without the bola-lipid core, nor the dendron entity dendron4A, nor the bola-core 1 led to any gene silencing (50 nM siRNA at $\mathrm{N} / \mathrm{P}=10$ ). (B) Dioleoylphosphatidylethanolamine (DOPE) enhanced the bola4A-mediated siRNA delivery and gene silencing (20 nM siRNA at N/P=10). (C) Bafilomycin A1 decreased the bola4A-mediated gene silencing ( $50 \mathrm{nM}$ siRNA at $\mathrm{N} / \mathrm{P}=10)$. PC-3 cells and Hsp27 siRNA were used. 
Scheme 1: Synthesis of the bola-amphiphilic dendrimer bola4A.

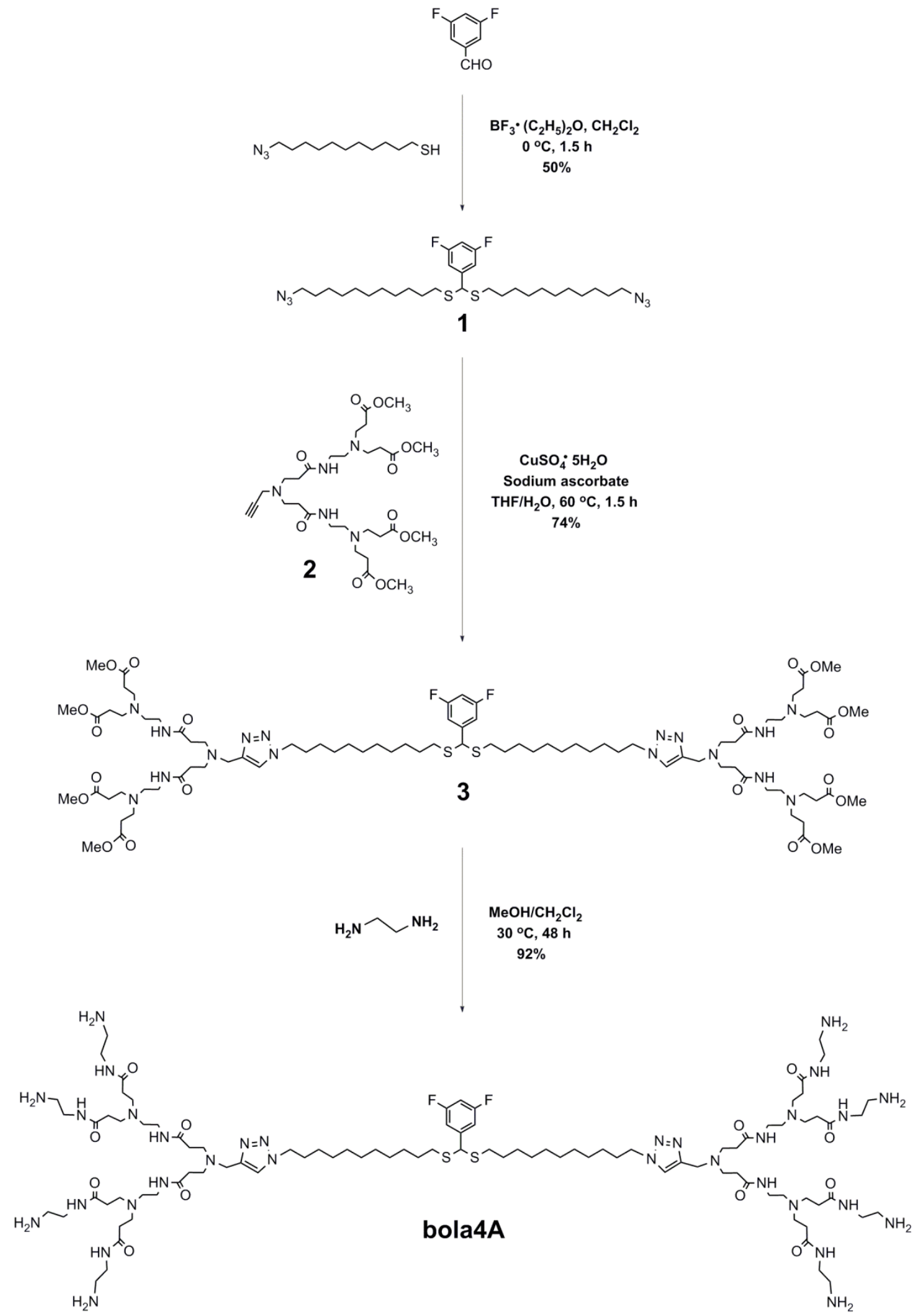


A

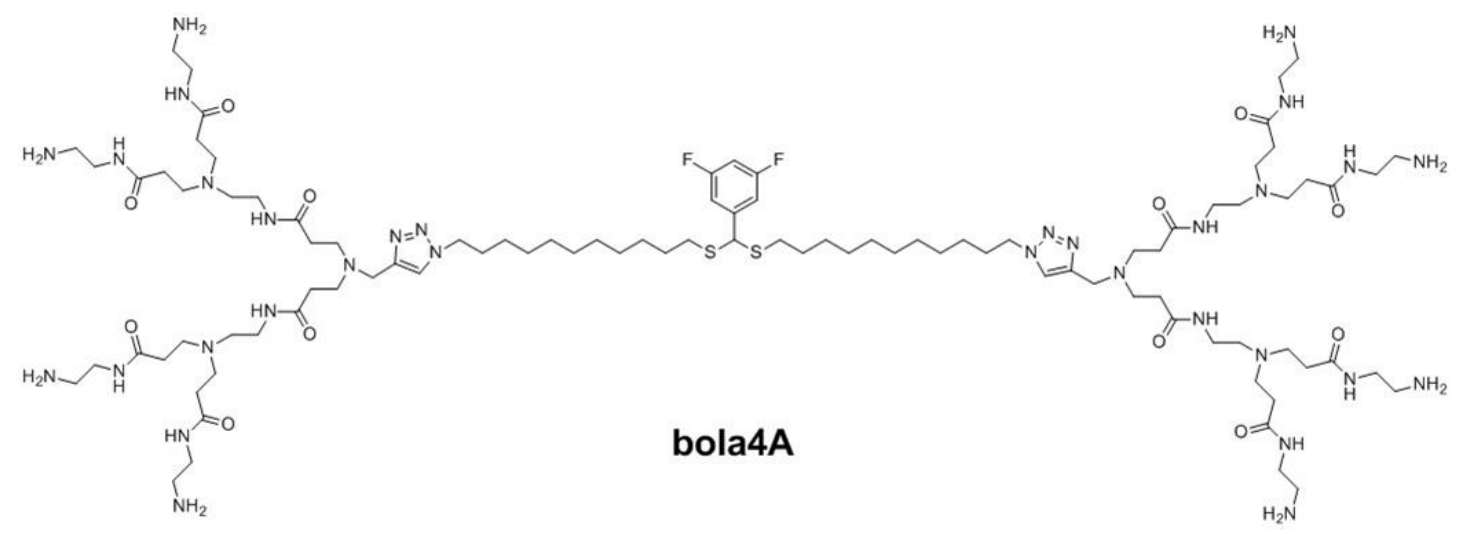

B

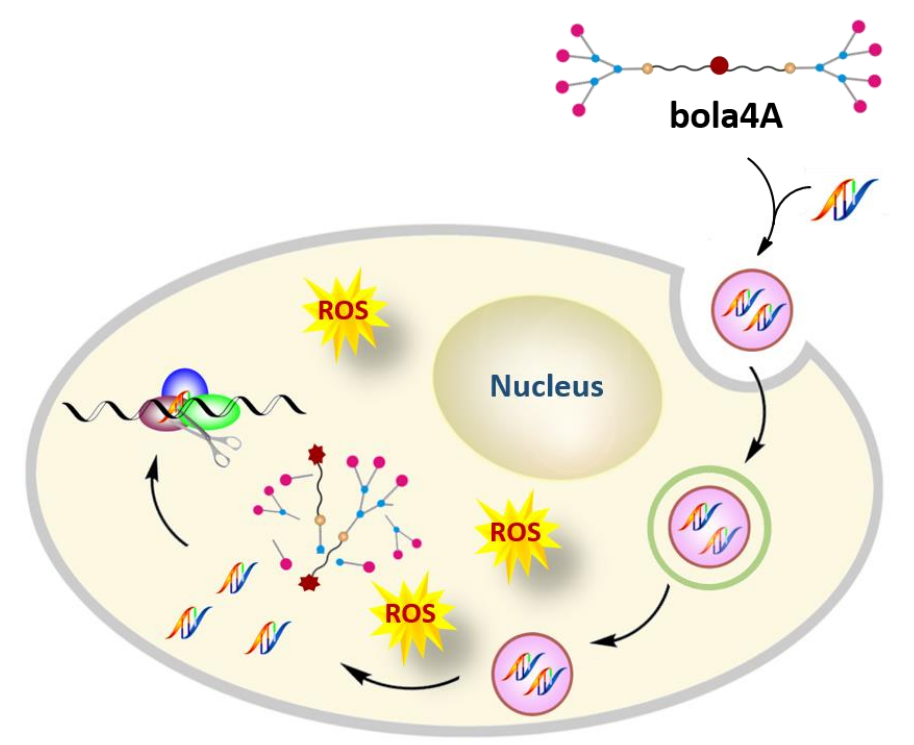

Figure 1: The bola-amphiphilic dendrimer bola4A, designed for ROS-responsive siRNA delivery. (A) Chemical structure of bola4A. (B) Schematic representation of bola4A for the ROS-triggered delivery of siRNA and consequential gene silencing. Bola4A dendrimers form complexes with siRNA molecules, which can be internalized by the cancer cell before releasing siRNA in response to ROS, leading to effective gene silencing. 

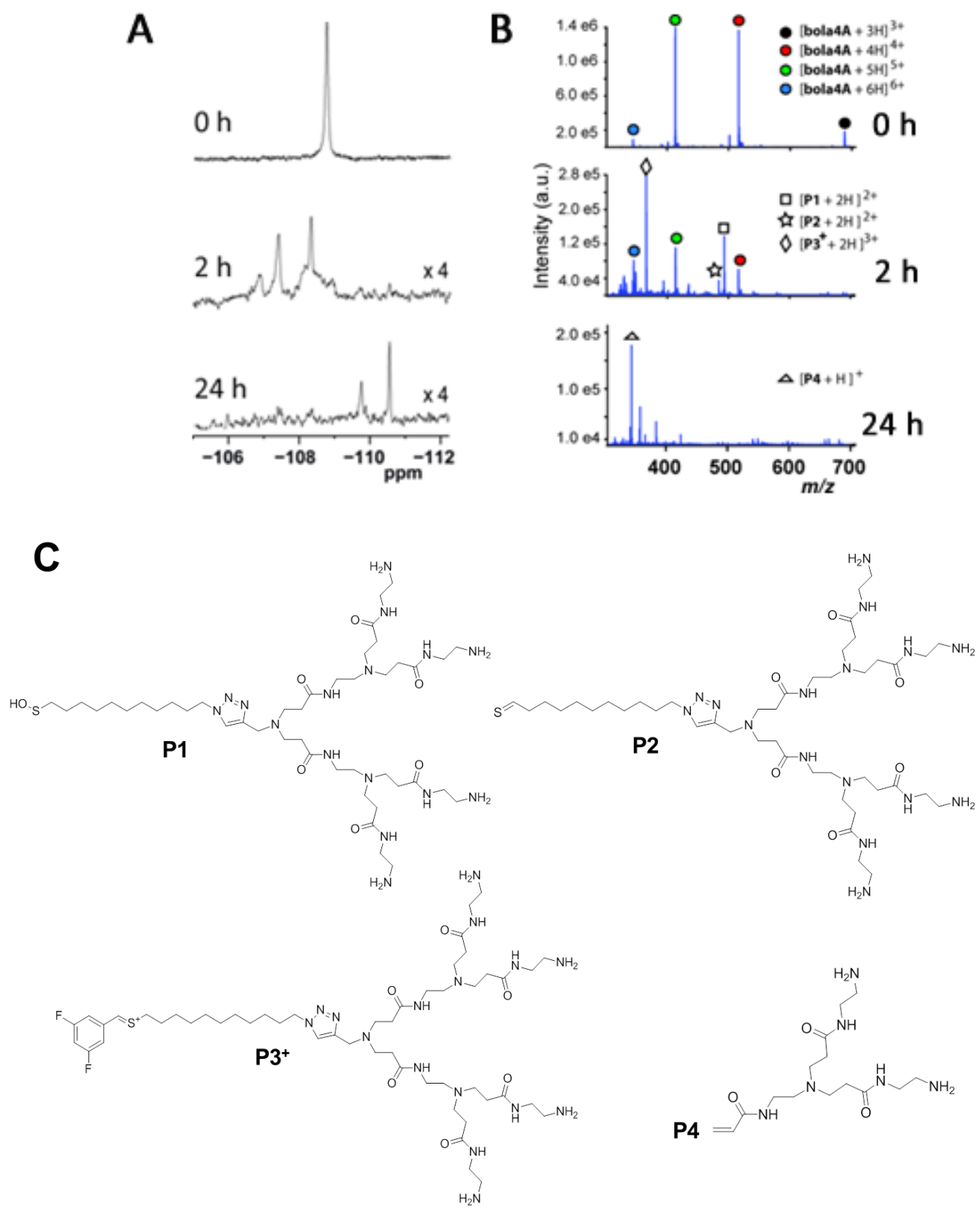

Figure 2: Study of bola4A decomposition upon treatment with $200 \mathrm{mM} \mathrm{H}_{2} \mathrm{O}_{2}$ (simulated $\mathrm{ROS}$ conditions) for 0, 2 and $24 \mathrm{~h}$, using (A) ${ }^{19} \mathrm{~F}-\mathrm{NMR}$ and (B) ESI-MS analysis. (C) Proposed structures, based on accurate mass measurements (Table S1), of degradation products of bola4A formed upon treatment with $\mathrm{H}_{2} \mathrm{O}_{2}$. 

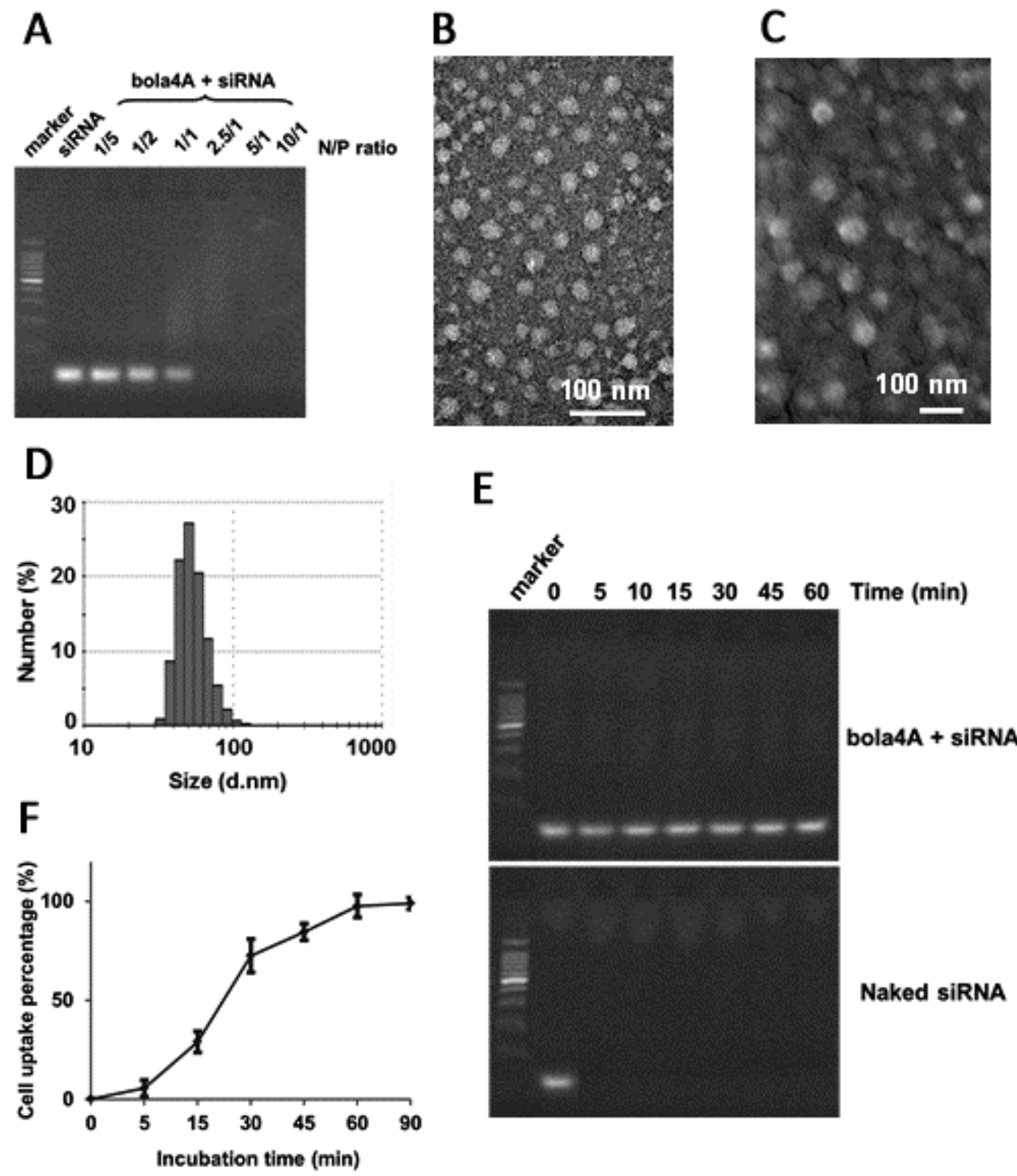

Figure 3: Bola4A is able to form nanocomplexes with siRNA, protect siRNA from degradation and promote cellular uptake. (A) Agarose gel migration of siRNA (200 ng per well) in the presence of bola4A dendrimer at N/P charge ratios of 1/5 - 10/1. (B) TEM image of the siRNA/bola4A complexes using $5 \mathrm{ng} / \mu \mathrm{L}$ siRNA and bola4A at an N/P ratio of 10. (C) SEM image of the siRNA/bola4A complexes using $5 \mathrm{ng} / \mu \mathrm{L}$ siRNA and bola4A at an N/P ratio of 10 . (D) Size distribution of the siRNA/bola4A complexes (at an N/P ratio of 10 with $1 \mu \mathrm{M}$ siRNA) determined using DLS. (E) Protection of siRNA by bola4A against enzymatic degradation. Compared to the naked siRNA (200 ng per well) which was degraded within 5 min in the presence of RNase, siRNA complexed with bola4A at an N/P ratio of 10 was resistant to RNase and remained stable even after $1 \mathrm{~h}$ incubation. (F) Uptake of Dy647-labeled Hsp27 siRNA/bola4A complexes (at an N/P ratio of 10 with $50 \mathrm{nM}$ siRNA) by human prostate cancer PC-3 cells evaluated using flow cytometry. Experiments were carried out in triplicate. 
A
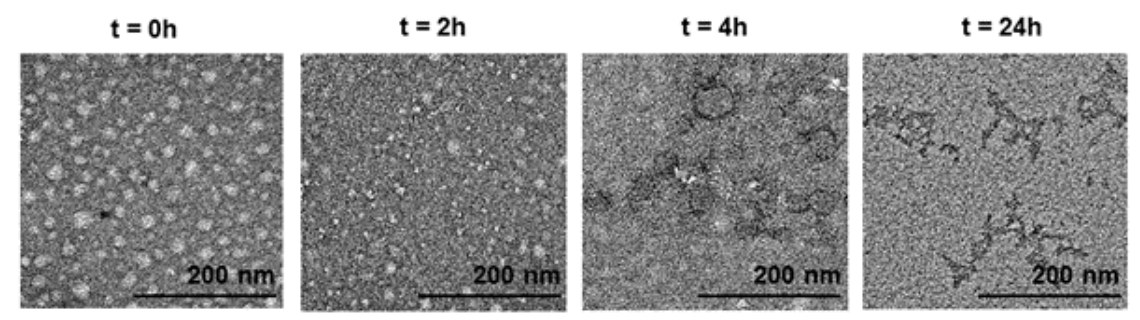

B

PC-3 cells

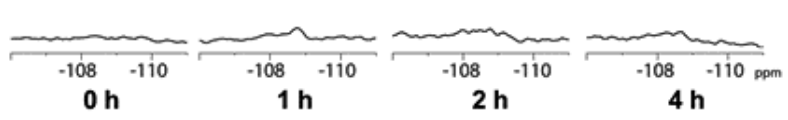

C
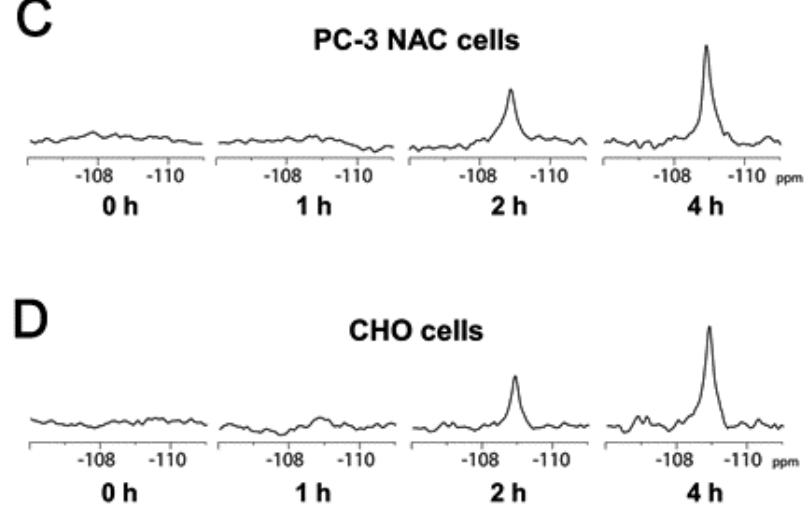

Figure 4: (A) TEM images of siRNA/bola4A complexes $(\mathrm{N} / \mathrm{P}=10)$ before and after incubation with $\mathrm{H}_{2} \mathrm{O}_{2}(1.06 \mathrm{M})$ for 2,4 and $24 \mathrm{~h}$ at $37{ }^{\circ} \mathrm{C}$. Scale bars indicate $200 \mathrm{~nm} .{ }^{19} \mathrm{~F}$ HRMAS NMR recording of bola4A at different time points $(0,1,2$ and $4 \mathrm{~h})$ in (B) ROS-rich normal prostate cancer PC-3 cells, (C) ROS-poor PC-3 cells pretreated with the antioxidant N-acetyl cysteine (NAC) and (D) ROS-poor Chinese hamster ovary $(\mathrm{CHO})$ cells after treatment with the siRNA/bola4A complexes. 
A

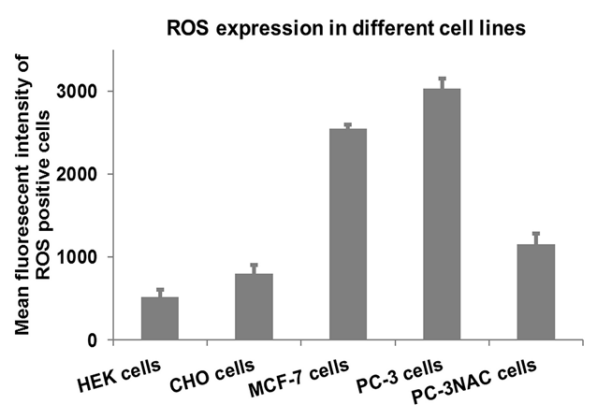

C

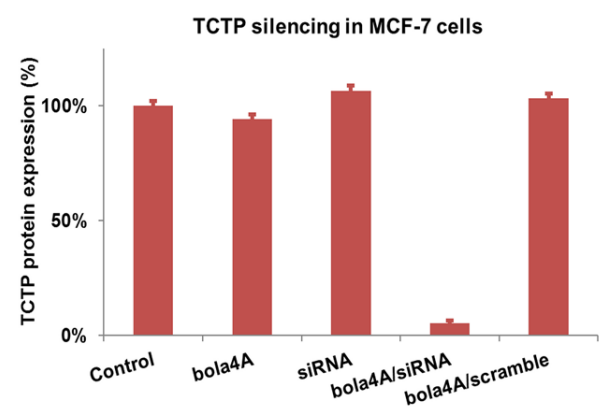

E

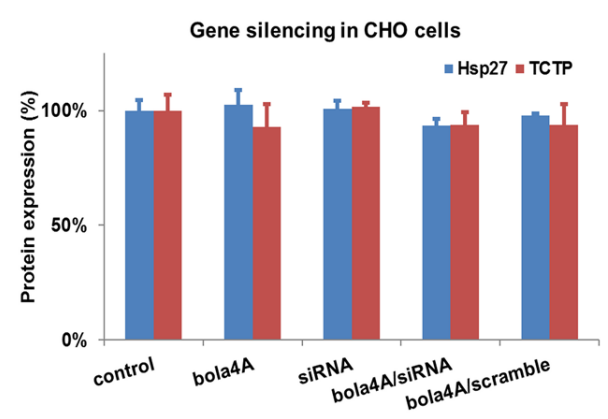

B

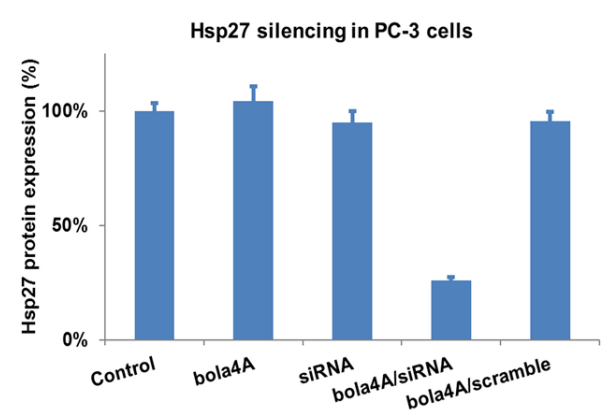

D

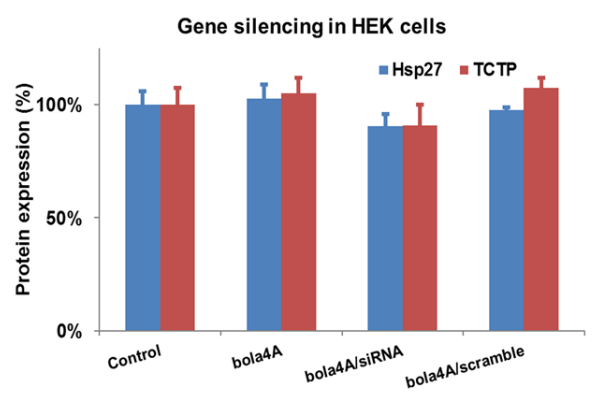

$\mathbf{F}$

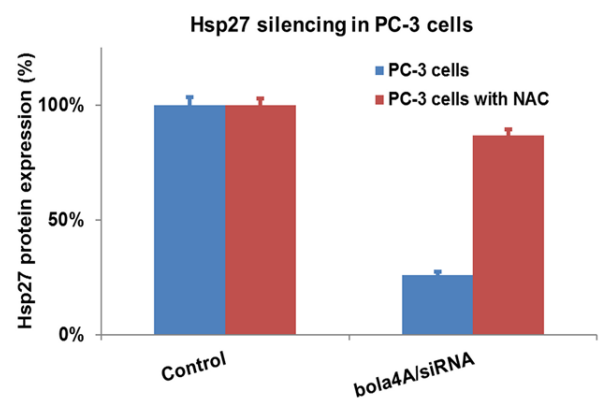

Figure 5: Bola4A-mediated specific and efficient ROS-responsive siRNA delivery and gene silencing. (A) ROS levels in Chinese hamster ovary (CHO) cells, human embryonic kidney (HEK) cells, breast cancer MCF-7 cells, prostate cancer PC-3 cells, and PC-3 cells pretreated with the antioxidant N-acetylcysteine (NAC) $(10 \mathrm{mM})$ quantified using CellROX ${ }^{\circledR}$ orange reagent by flow cytometry. Bola4Amediated siRNA delivery and gene silencing in ROS-abundant (B) PC-3 cells and (C) MCF-7 cells, as well as in ROS-poor (D) HEK cells, (E) CHO cells and (F) PC-3 cells pretreated with NAC (50 nM siRNA at $\mathrm{N} / \mathrm{P}=10$ ). SiRNAs targeting heat shock protein 27 (Hsp27) and translationally controlled tumor protein (TCTP) were used. 
A
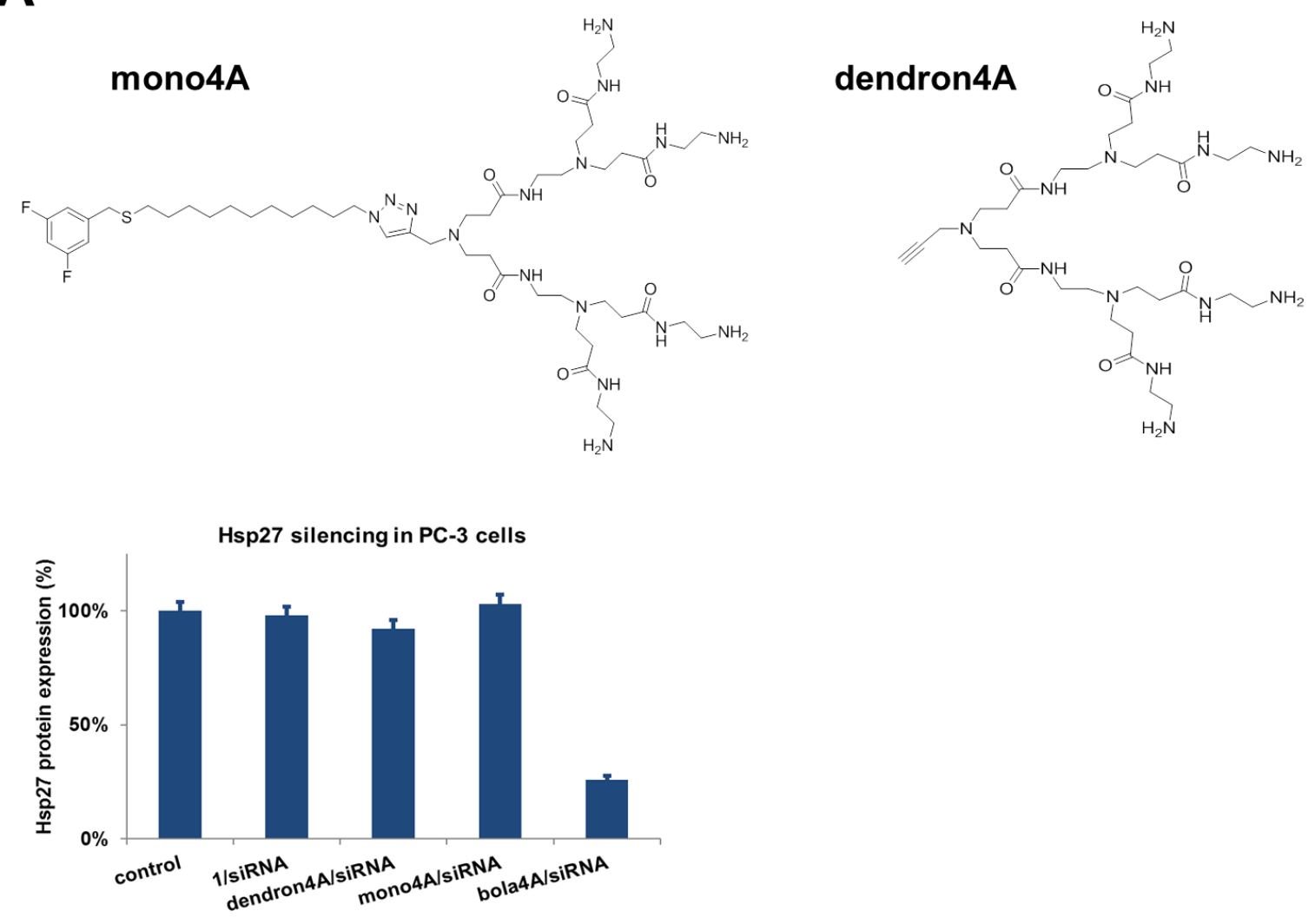

B

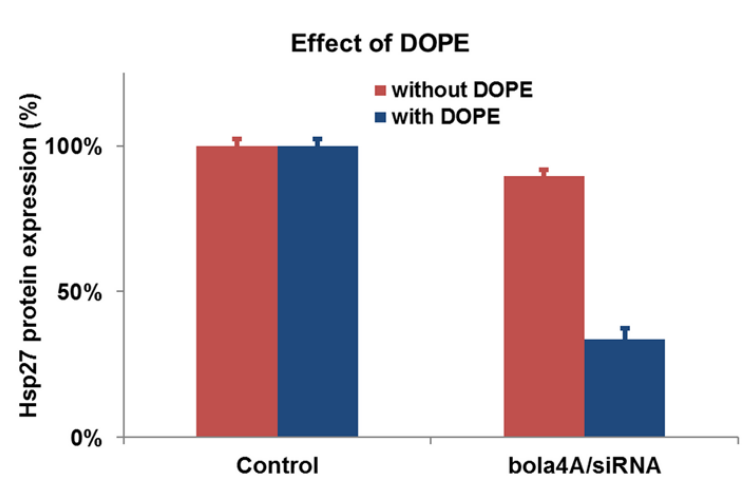

C

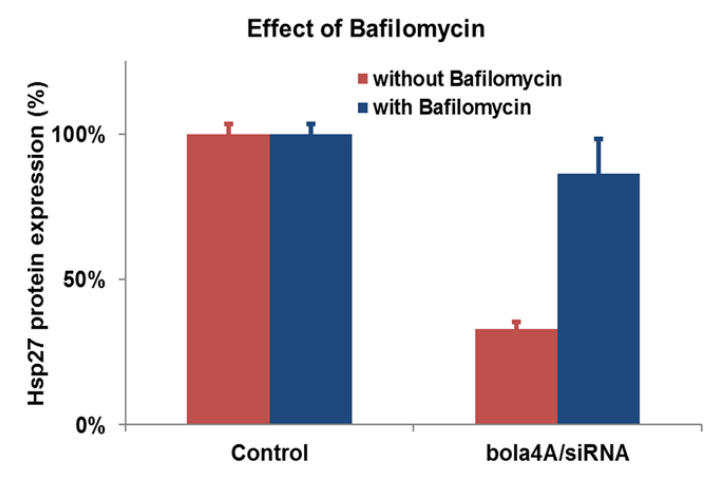

Figure 6: Bola4A-mediated siRNA delivery benefits from both the distinctive bola-amphiphilic structure and the delivery features of lipid and dendrimer vectors. (A) Compared to bola4A, neither the amphiphilic dendrimer mono4A without the bola-lipid core, nor the dendron entity dendron4A, nor the bola-core 1 led to any gene silencing $(50 \mathrm{nM}$ siRNA at $\mathrm{N} / \mathrm{P}=10)$. (B) Dioleoylphosphatidylethanolamine (DOPE) enhanced the bola4A-mediated siRNA delivery and gene silencing (20 nM siRNA at $\mathrm{N} / \mathrm{P}=10)$. (C) Bafilomycin A1 decreased the bola4A-mediated gene silencing ( $50 \mathrm{nM}$ siRNA at $\mathrm{N} / \mathrm{P}=10)$. $\mathrm{PC}-3$ cells and Hsp27 siRNA were used. 